\title{
Prevalence of Alveolar Domes by using Digital Panoramic Radiography
}

\author{
B. Vijay Kumar ${ }^{1}$, P. Amarnath Reddy ${ }^{2}$, J. Raviraj ${ }^{3}$, S.Venkat Suman ${ }^{4}$, SK Sameeulla ${ }^{5}$, K.N.V Praveen ${ }^{6}$, M. Rajendran ${ }^{7}$, \\ S. Jyotsna ${ }^{8}$ \\ ${ }^{1} \mathrm{HOD}$, Department of Oral Medicine and Radiology, ${ }^{2}$ Post graduate, Department of Oral Medicine and Radiology, ${ }^{3}$ Professor, \\ Department of Oral Medicine and Radiology, ${ }^{4}$ Reader, Department of Oral Medicine and Radiology, ${ }^{5}$ Reader, Department \\ of Oral Medicine and Radiology, ${ }^{6}$ Senior lecture, Department of Oral Medicine and Radiology, ${ }^{7}$ Post graduate, Department \\ of Oral Medicine and Radiology, ${ }^{8}$ Post graduate, Department of Oral Medicine and Radiology, CKS Theja Institute of Dental \\ Sciences and Research, Tirupati, India
}

Corresponding author: P. Amarnath Reddy, Post Graduate, Department of Oral Medicine and Radiology, Chadalawada Nagar, Tirupathi, India

DOI: http://dx.doi.org/10.21276/ijcmsr.2019.4.1.14

How to cite this article: B. Vijay Kumar, P. Amarnath Reddy, J. Raviraj, S.Venkat Suman, SK Sameeulla, K.N.V Praveen, M. Rajendran, S. Jyotsna. Prevalence of alveolar domes by using digital panoramic radiography. International Journal of Contemporary Medicine Surgery and Radiology. 2019;4(1):A58-A61.

\section{A B S T R A C T}

Introduction: Alveolar domes defined as anatomical projection of the root into floor of the maxillary sinus. Maxillary sinusitis is a disease that has a significant impact on a patient's health which may including facial pain, pain in maxilla region, toothaches, fatigue and nausea. Thus, knowing and identifying the relationship between dental roots and maxillary sinus is of utmost importance in determining proper diagnosis, planning and treatment.

Material and methods: 300 digital panoramic radiographs obtained from the data base of Dept of Oral Radiology, within age group of 20-50 years. To assess the prevalence of alveolar domes in the maxillary right and left side of the posterior teeth, compare the prevalence of alveolar domes between gender and age group and to verify the difference of alveolar dome shaped phenomena between the roots. Further, chi-square test was used for statistical analysis to assess the correlation of the prevalence of alveolar domes at various teeth, gender and age group.

Results: The prevalence of alveolar domes present in the right side of first pre-molars was statistically lower as compared to the other maxillary posterior teeth. No statistically significant difference was observed in the prevalence of alveolar domes between gender. Considering the alveolar domes at molar region according to roots, left side prevalence of alveolar domes in mesiobuccal root for first molar is higher compared to right side of mesiobuccal root of first molar, which is statistically highly significant.

Conclusion: Prevalence of alveolar domes showed that left side of the first $(64.3 \%)$ and second molars (64\%) presented a greater prevalence of alveolar domes especially in the mesiobuccal roots $(62 \%)$ followed by distobuccal and palatal roots. The first pre-molars presented a lower prevalence of alveolar domes.

Key words: Alveolar Domes; Maxillary Sinus; Prevalence; Digital Panoramic Radiography

\section{INTRODUCTION}

Maxillary sinus is the first of the paranasal sinuses to develop and ends its growth at approximately 20 years of age. ${ }^{1}$ The maxillary sinuses are normally segmented by septa and are located inside of the maxillary bones. ${ }^{2}$ These sinuses can present anatomical variations extending to the anterior region of the maxilla, maxillary tuberosity, hard palate, zygomatic bone, orbit and alveolar ridge. ${ }^{3}$ In this sense, the root apices of maxillary posterior teeth may well present a close relationship with the sinus floor. The knowledge of this anatomical relationship is essential when diagnosing changes in the sinus caused by lesions of odontogenic origin, surgical planning, intrusion of the maxillary sinus root, fracture of the bone plate with oral sinus communication, recognition of the pathway of dental infections and planning of orthodontic treatment. ${ }^{4,5}$ When there is a projection of the root into the maxillary sinus, the maxillary sinus floor deviates from its linear and horizontal path in order to bypass the dental root of the posterior teeth. This change is referred to as an 'alveolar dome' in this study. Maxillary sinusitis is a disease that has a significant impact on a patient's health, which may include facial pain, ear aches, pain in the maxilla region, toothaches, fatigue, irritability and nausea. ${ }^{6}$ Thus, knowing and identifying the relationship between these dental roots and the maxillary sinus is of utmost importance in determining proper diagnosis, planning and treatment. All previous studies have shown the anatomical relationship between the dental roots and the maxillary sinus through cone-beam computed tomography $(\mathrm{CBCT})$. However, $\mathrm{CBCT}$ is not considered for diagnosis due its high costs and radiation doses., ${ }^{2,47}$ The 
present study aimed to define the term 'alveolar dome' and to evaluate the prevalence of alveolar domes in the maxillary right and left sides of posterior teeth using digital panoramic radiographs.

\section{MATERIAL AND METHODS}

This study was conducted during a time period of four months, from August 2017 to November 2017. A total of 300 digital panoramic radiographs of patients who attended the Department of Oral Radiology in CKS Theja of Dental Sciences and Hospital, Tirupathi were examined. Digital panoramic radiographs were taken by using the NEWTOM Giano 3D machine. Only images of healthy maxillary sinus surrounding the teeth were included. Orthopantomographs of patients between the age group of 20-50 years were included in the study. Teeth with jaw fractues, poor radiographs were excluded from this study. In adults, the maxillary sinuses have a pyramidal shape extending from the root of the canine to the maxillary tuberosity, and from the floor of the orbit to the apex region of the maxillary posterior teeth. All of the images were evaluated by specialists in dental radiology and diagnostic imaging, after having been duly trained and calibrated. The interpretation of the digital images was performed directly with MICRO-DICOM software. These software was used to assess the prevalence of alveolar domes among the maxillary right and left posterior teeth, compare the prevalence of alveolar domes between gender and age group and to verify the difference of alveolar dome shaped phenomena between the roots. Further, chi-square test was used for statistical analysis to assess the correlation of the prevalence of alveolar domes among the maxillary right and left posterior teeth, gender, age group and difference of alveolar dome shaped phenomena between the roots.

\section{RESULTS}

\section{Prevalence of alveolar domes at various teeth}

Total of 300 digital panoramic radiographs of patients were assessed; 128 in female and 172 in male. Prevalence of alveolar domes were evaluated both right and left sides of maxillary posterior teeth. In right side prevalence of alveolar domes identified in first premolar was 16.3\% (49/300) which was statistically significantly lower when compared to second premolar 49\% (147/300), 62\% for first and second molars and $54.6 \%$ for third molar (148/271).

\begin{tabular}{|c|c|c|c|c|c|c|}
\hline \multirow[t]{2}{*}{ Tooth } & \multicolumn{3}{|c|}{ Right } & \multicolumn{3}{|c|}{ Left } \\
\hline & Present & Absent & Total & Present & Absent & Total \\
\hline First Premolar & $49(16.3)$ & $251(83.7)$ & 300 & $54(18)$ & $246(82)$ & 300 \\
\hline Second Premolar & $147(49)$ & $153(51)$ & 300 & $148(49.3)$ & $152(50.7)$ & 300 \\
\hline First Molar & $186(62)$ & $114(38)$ & 300 & $193(64.3)$ & $107(35.7)$ & 300 \\
\hline Second molar & $186(62)$ & $114(38)$ & 300 & $192(64)$ & $108(36)$ & 300 \\
\hline Third Molar & $148(54.6)$ & $123(45.4)$ & 271 & $157(58.3)$ & $110(41.7)$ & 267 \\
\hline$P$ value & \multicolumn{2}{|c|}{$<0.001^{* *}$} & & \multicolumn{2}{|c|}{$<0.001^{* *}$} & \\
\hline
\end{tabular}

\begin{tabular}{|c|c|c|c|c|c|c|}
\hline \multirow[t]{2}{*}{ Tooth } & \multicolumn{3}{|c|}{ Right } & \multicolumn{3}{|c|}{ Left } \\
\hline & Male & Female & Total & Male & Female & Total \\
\hline First Premolar & $23(13.4)$ & $26(20.3)$ & 300 & $28(16.3)$ & $26(23.3)$ & 300 \\
\hline Second Premolar & $81(47.1)$ & $66(51.6)$ & 300 & $82(47.7)$ & $66(51.6)$ & 300 \\
\hline First Molar & 103 (59.9) & $83(64.8)$ & 300 & $108(62.8)$ & $85(66.4)$ & 300 \\
\hline Second molar & $102(59.3)$ & $84(65.6)$ & 300 & $107(62.2)$ & $85(66.4)$ & 300 \\
\hline Third Molar & $84(48.8)$ & $64(50)$ & 271 & $88(51.2)$ & 69 (53.9) & 267 \\
\hline$P$ value & \multicolumn{2}{|c|}{$0.830 \mathrm{NS}$} & & \multicolumn{2}{|c|}{0.764 NS } & \\
\hline \multicolumn{7}{|c|}{ NS- Not significant $(p>0.05)$} \\
\hline
\end{tabular}

\begin{tabular}{|c|c|c|c|c|c|c|c|c|}
\hline \multirow[t]{2}{*}{ Side } & \multirow[t]{2}{*}{ Tooth } & \multicolumn{2}{|c|}{$20-30$ years $(\mathrm{N}=152)$} & \multicolumn{2}{|c|}{$30-40$ years $(\mathrm{N}=86)$} & \multicolumn{2}{|c|}{ 40-50 Years $(\mathrm{N}=62)$} & \multirow[t]{2}{*}{$P$ value } \\
\hline & & $\mathbf{N}$ & $\%$ & $\mathbf{N}$ & $\%$ & $\mathbf{N}$ & $\%$ & \\
\hline \multirow[t]{4}{*}{ Right } & First Premolar & 38 & 25 & 9 & 10.5 & 2 & 3.2 & $<0.001^{* *}$ \\
\hline & Second Premolar & 100 & 65.8 & 32 & 37.2 & 15 & 24.2 & $<0.001 * *$ \\
\hline & First Molar & 121 & 79.6 & 47 & 54.7 & 18 & 29 & $<0.001^{* *}$ \\
\hline & Second molar & 121 & 79.6 & 47 & 54.7 & 18 & 29 & $<0.001 * *$ \\
\hline \multirow[t]{4}{*}{ Left } & First Premolar & 41 & 27 & 11 & 12.8 & 2 & 3.2 & $<0.001 * *$ \\
\hline & Second Premolar & 100 & 65.8 & 36 & 41.9 & 12 & 19.4 & $<0.001^{* *}$ \\
\hline & First Molar & 123 & 80.9 & 51 & 59.3 & 19 & 30.6 & $<0.001 * *$ \\
\hline & Second molar & 123 & 80.9 & 51 & 59.3 & 18 & 29 & $<0.001 * *$ \\
\hline
\end{tabular}




\begin{tabular}{|c|c|c|c|c|c|c|c|c|}
\hline \multirow{3}{*}{$\begin{array}{l}\text { Side } \\
\text { Root }\end{array}$} & \multicolumn{4}{|c|}{ Right } & \multicolumn{4}{|c|}{ Left } \\
\hline & \multicolumn{2}{|c|}{ first molar } & \multicolumn{2}{|c|}{ second molar } & \multicolumn{2}{|c|}{ first molar } & \multicolumn{2}{|c|}{ second molar } \\
\hline & Present & Absent & Present & Absent & Present & Absent & Present & Absent \\
\hline Mesiobuccal root & $179(59.7)$ & $121(40.3)$ & $176(58.7)$ & $124(41.3)$ & $186(62)$ & $114(38)$ & $183(61)$ & $117(39)$ \\
\hline Distobuccal root & $151(50.3)$ & 149 (49.7) & $150(50)$ & $150(50)$ & $162(54)$ & $138(46)$ & $163(54.3)$ & $137(45.7)$ \\
\hline Palatal Root & $12(4)$ & $288(96)$ & $6(2)$ & $294(98)$ & $7(2.3)$ & $293(97.7)$ & $3(1)$ & $297(99)$ \\
\hline Total & \multicolumn{2}{|c|}{300} & \multicolumn{2}{|c|}{300} & \multicolumn{2}{|c|}{300} & \multicolumn{2}{|c|}{300} \\
\hline$P$ value & \multicolumn{2}{|c|}{$<0.001^{* *}$} & \multicolumn{2}{|c|}{$<0.001^{* *}$} & \multicolumn{2}{|c|}{$<0.001 * *$} & \multicolumn{2}{|c|}{$<0.001^{* *}$} \\
\hline
\end{tabular}

In left side prevalence of alveolar domes identified in first premolar was $18 \%$ (54/300) which was statistically significantly lower when compared to second premolar $49.3 \%$ (148/300), 64.3\% for first molar, 64\% for second molar and $58.3 \%$ for third molar (110/267). In left side prevalence of alveolar domes for first and second molars higher compared to right side of first and second molars which is highly statistically significant. (Table 1)

\section{Prevalence of alveolar domes according to gender}

Prevalence of alveolar domes according to gender were evaluated in right side identified $59.9 \%$ (103/172) in male and $64.8 \%(83 / 128)$ in females for first molar. Whereas left side identified $62.8 \%(108 / 172)$ in males and $66.4 \%$ $(85 / 128)$ in females for first molar, there is no statistically significant difference present in the alveolar domes in males and females. (Table 2)

\section{Prevalence of alveolar domes according to age group}

20- 50 years of age group were evaluated prevalence of alveolar domes but 20 -30 year age group higher prevalence compared to 30- 40 and 40-50 year of age group which is statistically highly significant. In 20- 30 years of age group prevalence on right side identified $25 \%$ for first premolar, $65.5 \%$ for second premolar, $79.9 \%$ for first molar and $79.6 \%$ for second molar. Whereas left side identified $27 \%$ for first premolar, $65.8 \%$ for second premolar, $80.9 \%$ for first and second molars. Here 20-30 years of age group prevalence on left side is more compared to right side which is statistically significant. (Table 3)

\section{Comparison of alveolar domes at molar region according} to roots

In the evaluation of the presence of alveolar domes among the roots of right side of first molar was observed more in mesiobuccal root (59.7\%) compared to distobuccal (50.3\%) and palatal root. Whereas left side of first molar was observed more in mesiobuccal root (62\%) compared to distobuccal (54\%) and palatal root. In left side prevalence of alveolar domes in mesiobuccal root for first molar is higher compared to right side of mesiobuccal root of first molar, which is statistically highly significant. (Table 4)

\section{DISCUSSION}

Most of the previous prevalence studies on alveolar domes were done with CT and CBCT. In present study using Digital panoramic radiographs because of less radiation exposure and low cost compared to CT and CBCT. Due to the anatomical proximity between the maxillary sinus and the root apices of right and left side of the maxillary posterior teeth were diagnosing various cases of maxillary sinusitis are of odontogenic origin or association with periapical and periodontal lesions. ${ }^{8}$ In addition to the endodontic treatment of pre-molars and molars can lead to such as oral sinus communication allowing for the displacement of infected tissues to the inner portion of the maxillary sinus. Kilic et $\mathrm{al}^{2}$ assessed 87 right and 89 left maxillary posterior regions from 92 patients using CBCT images then explained the roots of the first pre-molars had less contact with the maxillary sinus, whereas the buccal roots of the second molars had more contact to sinus. Pagin et $\mathrm{al}^{9}$ conducted using CT images, verified prevalence of the root apices protruded into the maxillary sinus in $21.1 \%$ of the first pre-molars, $22.2 \%$ of the second pre-molars, $20.3 \%$ of the first molars, $25 \%$ of the second molars, and $11.1 \%$ of the third molars. Santos xambre et $\mathrm{al}^{10}$ was observed that the root apices protruded into the maxillary sinus in $7.75 \%$ of the first pre-molars, $19.25 \%$ of the second pre-molars, $30 \%$ of the first molars, $32 \%$ of the second molars, and $22.66 \%$ of the third molars. In present study Prevalence of alveolar domes were evaluated both right and left sides of maxillary posterior teeth. In right side prevalence of alveolar domes identified in first premolar was $16.3 \%$ (49/300), for second premolar 49\% (147/300), 62\% for first and second molars and 54.6\% for third molar (148/271). In left side prevalence of alveolar domes identified in first premolar was $18 \%$ (54/300), for second premolar $49.3 \%$ (148/300), 64.3\% for first molar, 64\% for second molar and $58.3 \%$ for third molar (110/267). In left side prevalence of alveolar domes for first and second molars higher compared to right side of first and second molars which is highly statistically significant. This affirmation can be explained by the anatomy of the maxillary sinus which shows a tendency towards a reduction in volume in the medial and posterior directions. ${ }^{11}$ No previous studies evaluated prevalence of alveolar domes based on age. In present study 20 -30 year age group higher prevalence compared to $30-40$ and $40-50$ year of age group which is statistically highly significant. Here 2030 years of age group prevalence on left side is more compared to right side which is statistically significant. Freisfeld et $\mathrm{al}^{12}$ found that out of 129 roots, 64 seemed to penetrate into the maxillary sinus in the panoramic radiographs, but only 37 roots showed penetration in the CT. Santos xambre et al observed a lower prevalence of alveolar domes in the Palatal roots, when compared to the buccal roots $(\mathrm{p}<0.05)$. However, no statistically significant difference was observed between the $\mathrm{MB}$ and $\mathrm{DB}$ roots. Kwak et $\mathrm{al}^{13}$ observed 24 sides of 
maxilla of hemi-sectioned korean heads then explained distobuccal root second molar higher prevalence compared to first premolar. Frey et $\mathrm{al}^{14}$ observed with Denta scan showed mesiobuccal root of first and second molar has higher prevalence compared to distobuccal root of first and second molar. In present study evaluation of the presence of alveolar domes among the roots left side prevalence of alveolar domes in mesiobuccal root for first molar was higher compared to right side of mesiobuccal root of first molar and similar to distobuccal root for first molar, which was statistically highly significant. Palatal root showed less prevalence of alveolar domes. However, Digital panoramic radiographs have the advantage of being an imaging method that is more commonly used by dentists due to their cost, accessibility, and lower radiation dose. Once the digital panoramic radiograph has identified an alveolar dome, the decision to recommend for $3 \mathrm{D}$ imaging should be based on the patient's history and clinical examination. Then finally use of Digital panoramic radiographs is a screening for patients but ideally correlated to $3 \mathrm{D}$ imaging radiographs.

\section{CONCLUSION}

In regard to prevalence showed that left side of the first (64.3\%) and second molars (64\%) presented a greater prevalence of alveolar domes especially in the mesiobuccal roots $(62 \%)$ followed by distobuccal and palatal roots. The first pre-molars presented a lower prevalence of alveolar domes. Although the digital panoramic radiograph is a twodimensional method, the results of this study showed that digital panoramic radiographs can provide dentists with the auxiliary information necessary to identify alveolar domes, improving diagnosis, planning and treatment.

\section{REFERENCES}

1. Misch CE. Contemporary implant dentistry. 2nd ed. St.Louis: CV Mosby Co, 1999:76-194.

2. Kilic C, Kamburoglu K, Yuksel SP, Ozen T. An assessment of the relationship between the maxillary sinus floor and the maxillary posterior teeth root tips using dental cone-beam computerized tomography. Eur J Dent 2010; 4(2): 462-7.

3. Lana JP, Carneiro PM, Machado Vde C, de Souza PE, Manzi FR, Horta MC. Anatomic variations and lesions of the maxillary sinus detected in cone beam computed tomography for dental implants. Clin Oral Implants Res 2012; 23(1): 1398-403.

4. Hauman $\mathrm{CH}$, Chandler NP, Tong DC. Endodontic implications of the maxillary sinus: a review. Int Endod J 2002; 35(3): 127-41.

5. Sharan A, Madjar D. Correlation between maxillary sinus floor topography and related root position of posterior teeth using panoramic and cross-sectional computed tomography imaging. Oral Surg Oral Med Oral Pathol Oral Radiol Endod 2006; 102(5): 375-81.

6. Kretzschmar DP, Kretzschmar JL. Rhinosinusitis: review from a dental perspective. Oral Surg Oral Med Oral Pathol Oral Radiol Endod 2003; 96(4): 128-35.

7. Didilescu A, Rusu M, Sandulescu M, Georgescu C, Ciuluvica R. Morphometric analysis of the relationships between the maxillary first molar and maxillary sinus floor. Open J Stomatol 2012; 2(3): 352-7.

8. Patel NA, Ferguson BJ. Odontogenic sinusitis: an ancient but under-appreciated cause of maxillary sinusitis. Curr Opin Otolaryngol Head Neck Surg 2012; 20(1): 24-8.

9. Pagin O, Centurion BS, Rubira-Bullen IR, Alvares Capelozza AL. Maxillary sinus and posterior teeth: accessing close relationship by cone-beam computed tomographic scanning in a Brazilian population. J Endod 2013; 39(2):748-51.

10. Xambre PA, Valerio CS, E Alves Cardoso CA, Custódio AL, Manzi FR. The use of digital periapical radiographs to study the prevalence of alveolar domes. Imaging Sci Dent. 2016; 46(3):179-84.

11. Mossa-Basha M, Blitz AM. Imaging of the paranasal sinuses. Semin Roentgenol 2013; 48(5): 14-34.

12. Freisfeld M, Drescher D, Schellmann B, Schüller H. The maxillary sixth-year molar and its relation to the maxillary sinus. A comparative study between the panoramic tomogram and the computed tomogram. Fortschr Kieferorthop 1993; 54(6):179-186.

13. Kwak HH, Park HD, Yoon HR, Kang MK, Koh KS, Kim HJ. Topographic anatomy of the inferior wall of the maxillary sinus in Koreans. Int J Oral Maxillofac Surg 2004; 33(1): 382-8.

14. Fry RR, Patidar DC, Goyal S, Malhotra A. Proximity of maxillary posterior teeth roots to maxillary sinus and adjacent structures using Denta scan. Indian J Dent 2016; 7(3):126-130.

Source of Support: Nil; Conflict of Interest: None

Submitted: 10-12-2018; Accepted: 02-03-2019; Published online: 13-03-2019 